\title{
PROCESSING POSSESSIVES IN TRANSLATION BETWEEN UNEQUAL SYSTEMS: AN EXPLORATORY STUDY
}

\author{
BERGLJOT BEHRENS \\ University of Oslo
}

A BS T R ACT

The present paper reports on the results of two translation experiments conducted with eye tracking and keylogging. Norwegian and Danish professional and student translators have each translated a small English news text into their L1. The texts include possessives in different syntactic environments which entail a choice between a reflexive and an irreflexive form in the target texts. While native speakers are expected to make uniform choices that conform to regularities on local and non-local binding principles in Danish and Norwegian, disparate solutions have been found among the participants in both groups. The study compares final products with process data, both in terms of edits and in terms of temporal measures indicative of translation effort. Results show a considerable amount of hesitation on choice in all non-finite clause constructions, albeit more so among students than among professionals. Questions of translation effects versus an unstable locality principle are taken up in the final discussion.

\section{[1] INTRODUCTION}

This paper ${ }^{1}$ deals with grammatical choices made by translators who translate into their mother tongue. The underlying question is whether some of the cognitive mechanisms that are at work in translation into L1 are similar to those that are at work in advanced L2 production. In view of the previous chapters, Pitz et al. (2017) and Helland (2017), which deal with written Norwegian L2 production, the present chapter concentrates on translation into L1.

In an earlier paper (Behrens 2006), based on contrastive product data, I present some evidence to the effect that advanced L2 production and translation into L1 may reside in similar underlying mechanisms. Online L2 production and translation into L1 consist in verbalizing messages or thoughts conceived as selected from

[1] I would like to express my thanks to MA Alois Heuboeck from the University of Reading for his excellent and extremely valuable help in formulating my hypotheses in accordance with requirements for statistical testing, and for all the statistic tests presented in the results. Without his clever assistance, no statistics but for some simple descriptive measures could have been included. 
knowledge in long-term memory or on the basis of interpretation of another text. Very advanced L2 speakers can be expected to know all the 'rules' of their L2, but do not always make use of them (Carroll \& von Stutterheim 1993). The question is whether translators working into their L1, also do not access all the internalized rules of their mother tongue when intensively engaged in two languages simultaneously. A well-grounded reason for posing the question is linked to observed priming effects, i.e. grammaticized or morpho-phonological features of the source language which carry over into the target. Several studies of bilinguals attest to simultaneous activation of their two languages, even in monolingual settings (Grosjean 1997; de Groot 1992; Kroll \& de Groot 1997).

Non-optimal solutions may also result as a consequence of time constraints which affect in-depth interpretation of the text being reproduced in translation, that is, the content is not truly internalized as a thought before it is formulated in the target language.

On the other hand, norms in a language may also be unstable, and allow for some variation (Ydstie 1998; Günthner 2011), or affect translation by overuse of either a source or a target norm. If some grammatical system or norm is unstable, on the move, so to speak, one will expect to find variation among L1 speakers, and on that account a system may be extremely difficult to disentangle even for advanced learners of the language. The results of the experiments reported on in the present paper are an indication that the possessive system in Danish and Norwegian may indeed be unstable.

As presented in Fabricius-Hansen et al. (2017), the Scandinavian languages, as opposed to English and other West-European languages, distinguish between reflexive and non-reflexive possessive determiners. Below (section [2]) I will briefly review the systems and the general syntactic constraints on their use. The goal of the present study is to investigate empirically how professional and nonprofessional translators handle the systemic difference in practice, and discuss whether potential variation in translation choices may be due to priming, a general translation learner effect or to a possible instability of the system itself.

The paper reports on product and process data showing how native speakers of the target language handle possessive determiners in translation from English. From a cognitive point of view, native speakers are expected to have internalized all the grammatical rules of their mother tongue, so the null hypothesis is that there should be no grammatical mistakes in the target. On the other hand, as already mentioned, priming is known to take place to some extent in translation, also in translation into one's L1. Observations have been made with respect to false friends (Koessler \& Derocquigny 1928) as well as to syntactic priming (Bangalore et al. 2015). It would therefore not be a great surprise if untrained translators are found to be primed by the source text to a greater extent than professionals, who are expected to be more consciously aware of priming. Largely through 
Think-Aloud-Protocols, expertise research has shown that experts have strong monitoring skills (Glaser \& Chi 1988; Jääskeläinen 2010), which means that they are better trained to keep the systems apart.

The main question to be discussed in this paper is: Are the rules for correct choice clearly represented in the minds of the translators? An answer to this question may be arrived at through an investigation into the following: (i) whether the choices made are unanimous across the population studied, (ii) whether translators find the choice of possessive form hard to make, and (iii) whether any potentially incorrect choice can be testified as priming only.

The paper reports on results from two eye-tracking and keylogging studies of translation from English into Norwegian and Danish, respectively. Each study has collected data from 24 participants divided between professional translators and language students with a high demand of English (see section [4]). Registered measures of reading times, translation duration and pauses will be used in combination with the participants' edits and final products to come closer to an answer to the questions posed above.

The structure of the paper is set out as follows: Section [2] gives a brief overview of the system in Norwegian/Danish as compared with English. Morphophonological similarities are taken up for questions of priming. Section [3] is a presentation of the two experiment texts with a focus on the syntactic environments of the possessives as a variable. Our hypotheses are also presented in this section. Section [4] describes the details of the experiments. Results are presented in section [5], and a general discussion of the results with recommendations for follow-up studies concludes the paper in section [6].

\section{[2] THE ENGLISH AND DANISH/NORWEGIAN POSSESSIVE SYSTEMS}

English has a simple possessive system whereby the possessive determiner is the same whether it refers back to a possessor (of the same gender and number) in the same clause (1a), across clauses within the same sentence ((1b) and (1e)) across sentences ((1c) and (1d)) or it refers back to an external, contextually relevant possessor (alternative reading of (1a)).

(1) a. Craig took his $_{\mathrm{i} / \mathrm{j}}$ dog for a walk.

b. John $n_{i}$ was in love with Mary. $\mathrm{He}_{\mathrm{i}}$ suspected that his $\mathrm{s}_{\mathrm{i}}$ feelings were not returned.

c. John $n_{i}$ was in love with Mary. His ${ }_{i}$ thoughts centered around her night and day.

d. The blind man $_{\mathrm{i}}$ bumped against the staircase and fell. Martin $\mathrm{j}_{\mathrm{j}}$ rushed over, picked up his ${ }_{i}$ cane and assisted him $\mathrm{i}_{\mathrm{i}}$ to the entrance.

e. Peter $\mathrm{i}_{\mathrm{i}}$ found the bag lying on his $\mathrm{s}_{\mathrm{i} / \mathrm{j}}$ desk in the office. 
The Scandinavian languages, on the other hand, make a distinction between the reflexive and the non-reflexive possessive, (see below, but also Fabricius-Hansen et al. (2017)). The Danish and the Norwegian systems are the same in all relevant respects but for the third person plural. ${ }^{2}$

The systemic difference between English and Danish/Norwegian means that the Norwegian or Danish translator of (1a)-(1e) has to decide on the linguistic role of the determiner's antecedent in order to choose the correct possessive in the target language. This may be the result of pragmatic inference based on the co-text (as in (1a) and (1d)), but correct choice is also grammatically constrained. Norwegian translations of (1) appear in (2) below. All the translations have the same syntactic form as the corresponding English source sentences in these examples.

(2) a. Craigi gikk en tur med hunden $\sin _{\mathrm{i}} / \mathrm{hans}_{\mathrm{j}}$.

b. John $n_{i}$ var forelsket i Mary. Han $_{i}$ mistenkte at følelsene hans $s_{i}$ ikke ble gjengjeldt.

c. John $_{\mathrm{i}}$ var forelsket i Mary . Tankene hans $_{\mathrm{i}}$ sirklet rundt henne $\mathrm{j}_{\mathrm{j}}$ dag og natt.

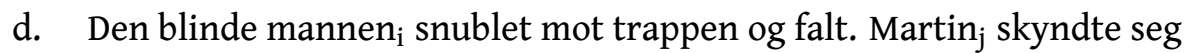
bort dit, plukket opp stokken (hans $\mathrm{i}_{\mathrm{i}}$ ) og hjalp ham $\mathrm{m}_{\mathrm{i}}$ opp til inngangen.

e. Peter $r_{i}$ fant vesken liggende på pulten $\sin _{\mathrm{i}} / \mathrm{hans}_{?_{\mathrm{i}} / \mathrm{j}}$ på kontoret.

When reference is found in the subject of the clause in which the possessive occurs, as in (2a), the reflexive $\operatorname{SIN}^{* 3}$ is the only correct choice. The non-reflexive HANS in the same example only allows the interpretation of an external referent. If the possessive appears in a finite sub-clause (as for example the Norwegian at (English that)-clause in (2b)), or in the following sentence (as in (1c) and (1d)), and the antecedent is only available in the matrix clause (2c) or the previous sentence (the pragmatic reading of (2d)), the non-reflexive possessive is the only correct choice. The general rule states that reflexive possessives (and reflexives generally) must be bound within the clause (local binding) (see references in Fabricius-Hansen et al. (2017)). Note in (2) that in the default, unmarked case in Norwegian, the possessive appears after the possessum. Pre-placement of the possessive also occurs in Norwegian but is constrained to a more formal register. If the possessive is pre-posed, the possessum appears without the definiteness marker (for example, the -en ending on the masculine noun). When it occurs after the possessum, definite marking on the noun is required. In Danish, pre-position is the default. Since pre- and post-position are both grammatically correct in Norwegian, although the latter is considered the more idiomatic choice, position will not be included as a variable in this study, although some mention of it will be

[2] The difference has no relevance for the present study.

[3] The reflexive is inflected for the gender of the possessum in Norwegian and Danish. SIN* or just SIN is used in the present paper as an abstraction from the individual genders of the possessum. 
made in the presentation of the results.

(1e) is an example of the possessive occurring in a non-finite participial clause. The same syntactic structure is available also in Norwegian in this example, although present participial clauses generally are much more constrained in Norwegian than in English (Faarlund et al. 1997; Kinn 2014).

In the translation, (2e), the reflexive possessive is normal, in spite of being bound by a referent outside the participial clause. A central question in this paper is how general this long distance binding is across different types of non-finite clauses. Norwegian has a highly restricted set of verbs that take present participial clauses (equivalent to English find someone V-ing; have someone V-ing; come V-ing + Compl). Also, the verbs taking the present participial morpheme in these contexts are generally intransitive and unbounded: for example, have someone staying $\rightarrow$ ha noen boende vs find someone taking a book from the shelf $\rightarrow$ *finne noen taende en bok fra hyllen. Norwegian differs in this respect quite radically from English -ing complements and adjuncts. ${ }^{4}$ Whether this means that the general rule of local binding is too strict, is somewhat unclear and will be considered in the discussion section towards the end of the paper. It should be noted that the adjunct phrase in (2e) (in his office) is free to attach to the main clause predicate (cf. found it in his office, lying on the desk) and not only to the subordinate clause. On such an analysis, the possessive is controlled locally, i.e. by the main clause subject, and the choice of a reflexive can be explained. On the other hand, if the prepositional phrase is attached to the subordinate participial clause, then, according to the general rule, the possessive should be HANS in order to be bound by the subject of the higher clause.

A more frequent non-finite clause type in Norwegian and Danish is the infinitive. The Norwegian reference grammar (Faarlund et al. 1997) establishes the general rule that the underlying PRO subject of the infinitive controls the reflexive possessive (Faarlund et al. 1997, 1162), but that occurrences of a reflexive possessive bound by the subject of the main clause are also attested. If the antecedent for the reflexive and the controller of the underlying PRO subject of the infinitive are different, but both in the third person singular, ambiguity may result. No study to my knowledge has made a systematic investigation into the binding restrictions on Norwegian possessives in non-finite clauses. ${ }^{5}$ An empirical study is underway Behrens \& Dirdal (To appear), as a follow-up of the present study. In the present study, the constraints have been set by agreement among a small group of colleagues, and will be referred to only in relation to the example types reported on

[4] Past-participle clauses also occur in Norwegian as predicative clauses. They are also interesting from the perspective of binding conditions for possessives, eg. henvist til rommet sitt ${ }_{i / 2 j} /$ hans $_{j}$, satte hunden $i$ i a bjeffe på Petter . Such structures are outside the scope of this paper.

[5] An exception is Lundquist (2014), who reports on a small study of what he calls 'mid-structures'. These are relevant for the present study, and are considered in the discussion section. 


\begin{tabular}{|c|c|c|c|}
\hline & \multirow[t]{2}{*}{ English } & \multicolumn{2}{|c|}{ Danish/Norwegian } \\
\hline & & Poss. refl. & Poss. non-refl \\
\hline First person sg./pl. & my/our & $\min ^{*} /$ vår* & $\min ^{*} /$ vår* \\
\hline Second person sg./pl. & your & din*/deres & din*/deres \\
\hline Third person sg. masc. & his & & hans \\
\hline Third person sg. fem. & her & $\sin *$ & hennes \\
\hline Third person sg. neut. & its & & dens* \\
\hline & their & deres $/ \sin ^{*}$ & deres \\
\hline
\end{tabular}

TABLE 1: The English and Danish/Norwegian possessive systems.

in the present paper.

To complete the picture, it is worth mentioning that generally, possessives are dropped with inalienables in Norwegian, as mentioned in Fabricius-Hansen et al. (2017). 'Inalienables' is a term used to refer to nouns denoting parts of one's body, clothes, and the notion has often been extended to include other objects usually thought to be permanently owned - such as one's apartment, one's dog etc. English generally requires the possessive determiner in these contexts. Idiomatic translation from English into Norwegian (and Danish) would drop the possessive, viz. (3) below.

(3) a. He couldn't move his arm $\rightarrow$ Han kunne ikke røre armen. ('...the arm')

b. He put on his jacket/shoes $\rightarrow$ Han tok på seg jakken/skoene. ('...the jacket/shoes')

c. He had locked the door to his apartment. $\rightarrow$ Han hadde låst døren til leiligheten. ('...to the apartment')

Dropping the possessive altogether is also very common with the mention of objects whose ownership is given in the immediate context or otherwise pragmatically inferred to belong to a contextually salient referent. This is relevant for some of the examples discussed, e.g. (2d), and will be taken up below.

\section{[2.1] Morpho-phonological similarity across the languages}

What adds to the difficulty of acquiring the system(s) for an English learner of Norwegian or Danish is the morpho-phonological similarity between the Norwegian/Danish non-reflexive forms and the English possessives (first and third person masculine in particular), viz. table 1 below, which sums up the forms in the two systems. Morpho-phonological similarity is a well-known cause for priming. For first and second person singular there is furthermore, like English and German, no morphological distinction between the reflexive and the non-reflexive possessive. 
The morpho-phonological similarity between the English possessive determiners and the non-reflexive forms in Danish/Norwegian suggests that priming should yield a higher frequency of the non-reflexive forms in translation from English, even in syntactic environments that do not license them. There is a similar morpho-phonological similarity between German and Norwegian, but for this language pair, the similarity is with the Norwegian/Danish reflexive possessives: cf. German sein, which does not distinguish between a reflexive and a non-reflexive use, and the Norwegian reflexive sin, (see Fabricius-Hansen et al. (2017) and Pitz et al. (2017)). Germans who have not fully acquired the Norwegian system, would thus be expected to overuse the reflexive form (see evidence in Pitz et al. (2017)), while the English learners could be phonologically primed to overuse the non-reflexive form in the Scandinavian languages.

Translation requires a constant change of linguistic mode from one language to the other. While even true bilinguals are claimed always to have both languages active simultaneously when listening/reading or speaking/writing, as mentioned in the introduction, the degree to which they are both active is understood to be influenced by situational factors, such as the degree of involvement in the two languages in the situation. If the conversational context is monolingual, the non-used language is less active than for example in translation, where the bilingual continuously switches between the two modes of language use. Translation, therefore, is predicted to have higher priming effects than other modes of communication among bilinguals. Priming is here thought of in two ways: on the one hand, the morpho-phonological similarity between forms in the two languages (cognates) may influence the translator to choose the target form that is phonologically most similar to that of the source. On the other hand, the structure of the source clause may be copied into the target, even if it is not the most idiomatic structure in the target. The latter type of priming is considered a learner effect, as novice translators are known to have the urge not to leave implicit anything that is explicitly expressed in the source text.

\section{[3] POSSESSIVES IN COHERENT TEXT. VARIATION IN THEIR SYNTACTIC ENVIRONMENTS}

The texts used in the experiments (see appendix) are both naturally occurring English texts of approximately the same length taken from two English newspapers. DA - used in the Danish experiment - is a text about a male nurse sentenced for having killed four of his patients. The possessives occur in sentences 2 and 10 , in different syntactic configurations. NO is the text used in the Norwegian experiment, about a driver who beats a dog and the dog later returns the attack by ruining the driver's car. The possessives occur in the second and the third sentences of the text, in different syntactic configurations, the translation of which affect the choice of possessive. 
The relevant sentences from texts DA and NO appear in (4)-(7):

(4) Norris disliked working with old people. All of his victims were old, weak women with heart problems. (DA, sentence 10)

(5) Hospital nurse Colin Norris was imprisoned for life today for the killing of four of his patients. (DA, sentence 2)

(6) Exiting the vehicle, the driver reportedly kicked the prostrate animal before returning to his car, an onlooker claimed. (NO, sentence 3)

(7) The unnamed driver had found the dog sleeping in his favorite parking spot outside his home in Chongqing. (NO, sentence 2 )

The possessive in (4) finds its antecedent in the subject of the previous sentence. In (5) it occurs in a nominalization with an event nominal (the killing) determined by a regular definite article, and a noun phrase referring to the objects affected by the event (his patients). In (6), the possessive occurs in a gerund-participial clause headed by a conjunction and find s its antecedent in the subject of the higher clause (the driver). The antecedent fir the possessives in the two prepositional phrases in (7) is pragmatically inferred to be the subject of the higher clause (the driver).

Each example will be discussed in view of translation, and hypotheses to be tested with respect to each will be formulated in the next section.

\section{[3.1] Hypotheses relating to the Danish material}

The possessive in (4) finds its antecedent in the subject of the previous sentence. It thus parallels (1c) in section [2], where binding (in a loose sense) crosses a sentence boundary. Providing the same syntactic structure in the Danish translation, the non-reflexive possessive is the only correct choice, cf. (8):

(8) Norris $\mathrm{s}_{\mathrm{i}}$ brød sig ikke om at arbeide med ældre. Alle hans $\mathrm{i}_{\mathrm{i}} /{ }^{*}$ sine ofre var gamle, svage kvinder med hjerteproblemer.

The non-reflexive possessive in (8), the Danish translation of (4), is also the phonologically closest to the parallel English possessive. НyPOTHEsIs 1 to be tested is therefore that the same choice, the non-reflexive hans will be made by professionals and students alike without much hesitation. Hesitation, or uncertainty, will be measured in terms of edits and pauses in the key-logging data.

The possessive in (5) appears within a nominalization forming the complement of a preposition. The nominalized verb is not itself determined by a possessive, and there is thus no linguistic marker to tell what the underlying subject would be, although pragmatic inference would make the subject of the sentence (Norris) the likely subject. From a structural point of view, two translation alternatives are relevant: (i) a translation with the same nominal structure as the source, or (ii) an 
infinitive clause. Structural choice has consequences for choice of possessive.

Нуротнеsis 2A: With a nominalization in the target, there will be indecision with respect to choice of possessive across participants.

The background for this hypothesis is that the source allows two vaguely different readings: (i) a reading in which the subject of the embedding clause is read as the underlying subject of the nominalization. On this reading the possessive will have a local binder (identical to the subject of the matrix), and the possessive is reflexive. (ii) A second reading is available since the head noun of the nominalization does not have a specified underlying subject. On such a reading, the writer does not commit him/herself to who actually killed the patients. The determiner his points back to the higher subject, and the non-reflexive possessive should be chosen.

Hуротнеsis 2B: The choice of non-reflexive hans in a nominalized target structure is expected to occur more often with the professionals than with the students.

Our motivation for this hypothesis is that the reading that takes the nonreflexive requires more reflection on the interpretation.

For a verbal structure in the target (alternative (ii)), the possessive has a local binder in the underlying subject of the verb drabe 'kill', which is identical with the subject of the matrix clause. The reflexive possessive is therefore the only correct choice, according to the general rule.

НуротнеSIS 2C: All participants choosing a verbal structure in the target will use the reflexive possessive.

Verbalization of a nominalized structure is very common in translation from English to Danish/Norwegian. An equivalent alternative in English would be a participial clause for having killed four of his patients. Given the availability of both a nominal and a verbal form of a base with the same denotation in the source and the target language, I do not expect translation into a verbal form to take significantly more time than translation into a nominal form (HYPOTHESIS 2D).

Based on the different complexities of the two examples, HYPOTHEsIs $2 \mathrm{E}$ is that translation of (5) will require more effort than translation of (4). Effort will be measured according to the following variables: total reading time of the source unit (TrtS), Pause, DUR (the time needed to type the translation, see section [4] below) and Total reading time of the target unit (TrtT). When particularly relevant, regression path duration (RPDur) is also considered, i.e. the duration of the first fixations on the source unit, including the time a participant spends looking back into contextual information before going on to the next element (see section [4] below).

\section{[3.2] Hypotheses relating to the Norwegian material}

A similar comparison as done for the Danish material will be made for the Norwegian experiment data, although the syntactic structures in which the possessives 
occur are not identical. The similarity of the two sets lies in the observation that (4) as well as (6) have only one translation choice, while the second sentence in each set allow more syntactic variety which is expected to affect the translation of the possessive. The possessive in (6) appears in a conjunction-headed non-finite participial clause. ${ }^{6}$ From a contextual and pragmatic perspective, the car belongs to the driver, and the driver is therefore understood as the underlying subject of the participle. The anaphoric link to the vehicle exited by the driver at the beginning of the sentence makes this the only relevant reading. ${ }^{7}$ For Norwegian translation, the strong link between the (assumed) owner (the driver) and the car makes omission of the possessive not only possible, but also very likely. Moreover, Norwegian has no non-finite structure that can complement a conjunction. A finite structure is the only choice, meaning that a subject must be expressed in the clause. A pronominal subject he pointing back to the driver will bind the possessive locally, i.e. the reflexive possessive is the only correct choice. НyротнEsis 3A: The reflexive possessive sin will be chosen across participants unless it is dropped altogether. It is also expected that choice of possessive will not require much effort (HYPOTHESIS 3B). Since there is no phrase we can use as a baseline against which effort in terms of temporal processing times can be measured with reasonable certainty, this hypothesis can only be tested against measures of edits performed by the participants. Our нYРОтнЕSIs 3в will thus be confirmed if the participants do not make any edits on the possessive.

The likelihood of dropping the possessive altogether is expected to be higher among the professional translators than the students (HYPOTHESIs 3c). A student's lack of practice has often demonstrated more literal translations in the sense that no information made explicit in the source can be dropped, (personal experience). This observation suggests that the students have less access to the pragmatic rules of the target in the process of translating.

Since the phrase in (6) is unambiguous and has only one very regular target solution beyond the choice of dropping the reflexive altogether, the translation process is considered 'basic' enough for the process data to be used for comparison with the next example in the Norwegian text.

From a formal point of view, (7) is syntactically and semantically ambiguous. In classical generative terms, it exemplifies a case of raising. The object of the matrix clause (the dog) has been raised from the subject position of the subordinate

[6] According to grammars of English, the category membership of before and after is unclear. According to Huddleston \& Pullum (2002), they are prepositions only. This classification is problematic in that prepositions do not take finite clauses in English. Before and after do admit finite clauses, for example before/after he left, I called a friend. In Norwegian, the parallel to before, før, operates as a preposition and as a subordinating conjunction (Faarlund et al. 1997, 340). As a conjunction it takes a finite clause. Prepositions never take finite clauses in Norwegian. I therefore classify before as a conjunction.

[7] From a purely syntactic point of view, there is no given rule that prevents the object of the main clause to be available as the underlying subject of the participial clause. However, such an interpretation is hard to get and pragmatically impossible. 
clause, which is the participial clause in which the possessives occur. Formally, therefore, the possessives could be locally bound by this subject. From a pragmatic perspective, however, the possessives find reference in the subject of the main clause, the driver. It is very likely that the driver has a home and a parking spot outside it. It is highly unlikely, even contradictory, that a stray dog has a home and a parking spot. With the contextual information added, it is reasonable to expect that the reading of this sentence for comprehension should take no longer than the reading of (6), normalized by length. ${ }^{8}$ However, in view of the introductory remarks on possessives in non-finite clauses in section II, the general observations on reflexives in subordinate clauses make it hard to determine what translation choice can be expected. Furthermore, as was suggested for the participial clause in (2e) in section [2], the prepositional phrases with the possessives (as one unit) have two possible attachments: to the verb in the subordinate clause (sleeping), or to the verb in the main clause (found). On the latter account, the possessives are locally bound by the subject of the main clause, and providing the same structure in the target language, the correct choice is that of a reflexive possessive (SIN) to refer to the driver. On the account that it attaches to the lower clause, on the other hand, the pragmatically likely reading would require the non-reflexive possessive (HANS), to ensure co-reference with the subject of the higher clause. Choice of the reflexive on this analysis would indicate local binding (the unlikely reading).

With the ambiguity in mind, and in view of findings in the literature to the effect that reading for translation involves at least some activation of translation alternatives, the reading of this example is expected to take longer than the reading of (6) (HYPOTHESIS 4A). Furthermore, more variety in choice of possessives both in the final products and in the number of edits in this example is expected as compared with (6) (нуротнеsis 4B). Consequently, choice of possessive is expected to take longer than in (6) for both groups (HYPOTHESIS 4C). Again, on the basis that students lack experience, and that they on that account may have less access to the pragmatic rules of the target in the translation situation, students are expected to follow the structure of the source with higher frequency than the professional translators will. In particular, since the possessives occur in two prepositional phrases and find their antecedent in the same referent (pragmatically inferred), mention of possession in both phrases is superfluous in Norwegian. НyPOTHESIS 4D is that double possessives will occur more often in the non-professionals' targets.

\section{[4] THE EXPERIMENTS}

The data extracted for this study consists of process and product data from two online translation experiments run with eye tracking and key logging. The EnglishNorwegian study conducted at the University of Oslo in 2015 comprises data col-

[8] This cannot be tested, since no participants were asked to read the text for comprehension only. 
lected from 25 participants, all with Norwegian as their mother tongue. The experiment was conducted with an SMI 500 eye tracker with a plug-in for Translog II. ${ }^{9}$ Translog II is a software logging among other things the times at which the informant's eyes are focused on a particular item in the source text or in the target text produced, the time it takes to read a word or a sequence of words, and the number of times an item is looked at. Regressions are also measured, that is, the amount of time it takes from the first fixation on an item until the eyes move on to the next word in the text. Importantly, it includes temporal measures for all eye movements back (regressions) to the left of the fixated word. Furthermore, all keyboard activities are logged, including measures of inactivity (calculation of pauses). This means all the revisions made before the final translation is typed in can be extracted from the tables, as well as the time lapse (pauses) between the translations of two items or two or more versions of an item. Duration (Dur) is a measure of the total time needed to type the final translation, in other words including all the typing activities related to the translation of that word or string.(For an overview of the variables measured in the output of the Translog II data, see Carl et al. (2015)).

The Danish data comes from the CRITT database. ${ }^{10}$ The Danish experiment was conducted by Hvelplund and was used as basis for his cognitive linguistic $\mathrm{PhD}$ study of translator behavior (Hvelplund 2011). Eye tracking and keylogging were registered by use of a Tobii60 eye tracker with Translog software. Both data sets of the present study have been collected according to the same experimental set up, with 24 and 25 informants, and with texts of about the same length (141 vs. 148 words). In each experiment, half of the group is advanced students of English with little or no translation experience, the other half are professional translators.

The logging data makes it possible to look into the ways in which the informants handle their translation tasks. Previous studies on translation behavior (see for example Jakobsen \& Jensen (2008)) show that reading for translation, as compared to reading only for comprehension, is slower. The saccades are shorter and the fixations are longer. This indicates very clearly that the purpose of the reading task has an important impact on the processing. A generally held interpretation of this behavioral difference is that the translator co-activates both source and target language during reading, and that some (pre-)translation is going on already in the first reading of a phrase or segment (Bangalore et al. 2015). With eye tracking technology, cognitive load (effort) in translation can consequently be measured based on reading times on relevant items or segments during a translation task. Along with the edits logged in the data, temporal measures of gaze on particular words or the reading of larger strings in the source or in the target are used as behavioral indicators of translation difficulties. An additional measure is the

[9] https://sites.google.com/site/centretranslationinnovation/tpr-db

[10] https://sites.google.com/site/centretranslationinnovation/tpr-db 
duration of pauses between unit productions. The analysis includes absolute frequencies on products and edits as well as temporal measures of Duration, Pauses and Total reading times of the source units and the target units.

The temporal measures are transformed for statistical tests ${ }^{11}$ as follows:

(i) Normalization: to account for the fact that the units analyzed are unequal in length, the measure is divided by the number of characters in the English source unit.

(ii) Aggregation: the mean value of all normalized numbers is computed for each participant over the whole phrase under consideration, excluding null values.

(iii) The data were log-transformed to account for skewness where relevant.

The results are mean normalized variables, on which the t-tests have been performed. Paired $t$-tests have been used for inference on the difference between corresponding measures of the same participant in different examples. Non-paired $\mathrm{t}$-tests have been used for inference on the difference between corresponding measures of groups of participants (mainly students versus professional translators). Equal variance has not been assumed in the tests, and the significance level chosen throughout is 0.05 .

Proportions of categorical variables (types of translation choices) are estimated as a $95 \%$ confidence interval. Due to small sample sizes, this has been done using bootstrapping. Sample sizes are provided for each data set considered in the results.

\section{[5] RESULTS}

[5.1] The Danish study: Absolute and statistical values Example 4: 'All of his victims...'

Table 2 gives the absolute frequencies of the choices made by the professionals and students for the unit 'all of his victims'. The results are identical for the two groups. Although one participant in each group chose to drop the possessive altogether, leaving possession to inference, the rest all chose the non-reflexive possessive in their translation. The fact that no participants chose the non-reflexive possessive is strong support for HYPOTHESIS 1.

There were no edits in the choice of possessive across students and professionals. Furthermore, the choices were uniform across participants but for one in each group. These facts are stipulated to indicate that the participants did not hesitate on their choice. Temporal measures for this example have been computed only for comparison with (5) (see below).

[11] $R$ version 3.3.0 was used for the statistics. 


\begin{tabular}{lrr}
\hline Group & Non-reflexive & Possessive dropped \\
\hline Professionals & 11 & 1 \\
Students & 11 & 1 \\
\hline
\end{tabular}

TABLE 2: Product results for (4).

\begin{tabular}{llrr}
\hline & [Norris]...blev fcengslet & Students & Professionals \\
\hline a) Verbalization + SIN & $\begin{array}{l}\text {...for at have drcebt fire af } \\
\text { sine patienter }\end{array}$ & 6 & 7 \\
b) Verbalization + HANS & $\begin{array}{l}\text {-..for at have drcebt fire af } \\
\text { hans patienter }\end{array}$ & 3 & 0 \\
c) Nominalization + SIN & $\begin{array}{l}\text { for drabet på fire af sine } \\
\text { patienter }\end{array}$ & 1 & 2 \\
d) Nominalization + HANS for drabet på fire af hans & 2 & 2 \\
e) No possessiventer & \begin{tabular}{l} 
for drab på fire patienter \\
\hline
\end{tabular}
\end{tabular}

TABLE 3: The different types of translation of (5) in Danish.

Example 5: '...for the killing of four of his patients'

Tables 3 and 4 show the results for the relevant phrase of (5), repeated here:

(5) Hospital nurse Colin Norris was imprisoned for life today for the killing of four of his patients. (DA, sentence 2)

Variation was predicted between a nominalized and a verbalized structure in the target. This is confirmed by the resulting products. Examples of the different structures, taken from the participant data, are listed in table 3.

Interestingly, the verbalized structure was chosen twice as often as the nominalized structure. There is no vacillation (in terms of edits) with respect to choice of a verbal or a nominal structure. Both are also equally acceptable translation choices. In view of the possible pragmatic readings of the source sentence (whether Norris actually is taken to be the agent of the killings, not just imprisoned for them), HYPOTHESIS 2A stated that the participants would vary in choice of possessive if a nominal structure was chosen. This hypothesis is confirmed by the absolute frequencies. Нүротнеsis 2B, however, is disconfirmed: the choice of a non-reflexive distributes with equal numbers (2-2) in both groups table 4.

The choice of a verbal structure in the target, on the other hand, has led to interesting differences between the two groups. All the professionals (seven participants) make the same reflexive target choice. As for the students, one third 


\begin{tabular}{lcccccc}
\hline & \multicolumn{2}{c}{ Nominalization } & & \multicolumn{2}{c}{ Verbalization (infinitive) } \\
\cline { 2 - 3 } \cline { 5 - 6 } & Professional & Student & & Professional & Student \\
\hline Reflexive & 2 & 1 & & 7 & 6 \\
Non-reflexive & 2 & 2 & & 0 & 3 \\
No possessive & 1 & & & & 0 & 0 \\
Sum 1 & 5 & & 3 & & 7 & 9 \\
Sum 2 & & 8 & & & & 16 \\
\hline
\end{tabular}

TABLE 4: Product results among professionals and students for (5).

(three out of nine) choose the non-reflexive possessive. Our HYPOTHESIs 2c, that the reflexive would be chosen across participants, is disconfirmed by the data. One might speculate that the students choosing the 'erratic' non-reflexive possessive are primed by the source, but the study gives no clear evidence of this.

A look at edits in the data for this example might indicate whether the participants hesitate in choosing between a reflexive and a non-reflexive form, thus demonstrating some conscious reflection and indecision on the choice, or not. The three participants choosing the non-reflexive form in the verbalized translation have no edits. However, hesitation is demonstrated in the overall data for this example, as two other students had the non-reflexive as her/his first choice in the verbal structure, but revised it to the reflexive during the production, and one professional translator edited her/his initial non-reflexive choice to the reflexive during a second reading of the target.

Temporal measures may indicate whether the 'marked' choices are a matter of priming, or based on a more conscious decision. To test for this, the following four claims were postulated:

(i) The translation of the 'error' examples take less time (DUR average measured over the unit) than the rest of the student translations (irrespective of syntactic choice of the phrase).

(ii) TrtS and TrtT are significantly lower for the 'error' participants than for the rest of the students (or for the rest of the participants).

(iii) The regression path duration for the 'error' responses is no higher than the first fixation duration for the same responses (i.e. they do not look back into the context)

(iv) There is no pause duration for this choice.

The claims were tested by two-sided paired t-tests, with no equal variance assumed. The measures are based on normalization by length of the target phrases. 


\begin{tabular}{cccc}
\hline Min. & Max. & Median & Mean \\
\hline 46.19 & 110.6 & 47.73 & 68.17 \\
\hline
\end{tabular}

TABLE 5: Summary of the difference between normalized RPDur and FFDur.

The claims are not substantiated by the data. In fact, the mean of mean normalized duration is higher in the 'error' group than in the rest of the student group. Normalized TrtS and TrtT are higher in the 'error' group as compared with the rest of the student group as well as with the whole 'non-error' group together. As for (iii), t-tests indicate that regression path duration in the 'error' group in fact is higher than the first fixation duration, i.e. they do look back in context while reading. Differences between normalized RPDur (regression path duration) and FFDur (First Fixation duration) lie between 46.19 and 110.6. A summary of the difference is given in table 5 .

The claim that RPDur is no higher than FFDur is tested in two t-tests: the first, on the full data (comparing the two variables for each token and participant); and a second one on the aggregated data, comparing mean normalized RPDur and FFDur for each participant. Test 1 yielded a p-value of 0.002 , the second one a $p$ value of 0.042 , hence the data rejects the claim in (iii) and supports the alternative hypothesis that RPDur in the 'error' group is greater than FFDur.

Finally, the 'error' group has some values in the Pause variable, meaning that the claim in (iv) is contradicted. It should be noted that the 'error' group is very small, only 3 participants. Therefore, any generalizations to whole populations of student and professional translators should be taken with caution. However, the results may be indicative of a particular learner profile, as will be discussed further in section [6] below.

It was hypothesized that the verbal choice would not take significantly longer than the choice of a nominalized form. For this, the temporal measures for the $\mathrm{V}$ (erbal) target and the $\mathrm{N}$ (ominal) target of whole phrase the killing of four of his patients' were compared. The verbal form was found to take longer than the nominal form, although not at a significant level for any of the measures:

A t-test for Duration yielded a p-value of 0.163 and for Total reading time of the Source a p-value of 0.6 , both indicating higher values for the verbal target, although the results are not significant. The Pause measure was almost identical between the two, and the total reading time of the target yielded no obvious structure, so measures were not calculated.

For HYPOTHESIS 2C the phrases were restricted to four of his patients vs. all of his victims. Based on an expected difference in choice of possessive due to the different syntactic choices, the hypothesis was that the phrase in (5) would be more effortful to translate than the phrase in (4). The same analysis was performed on each of 


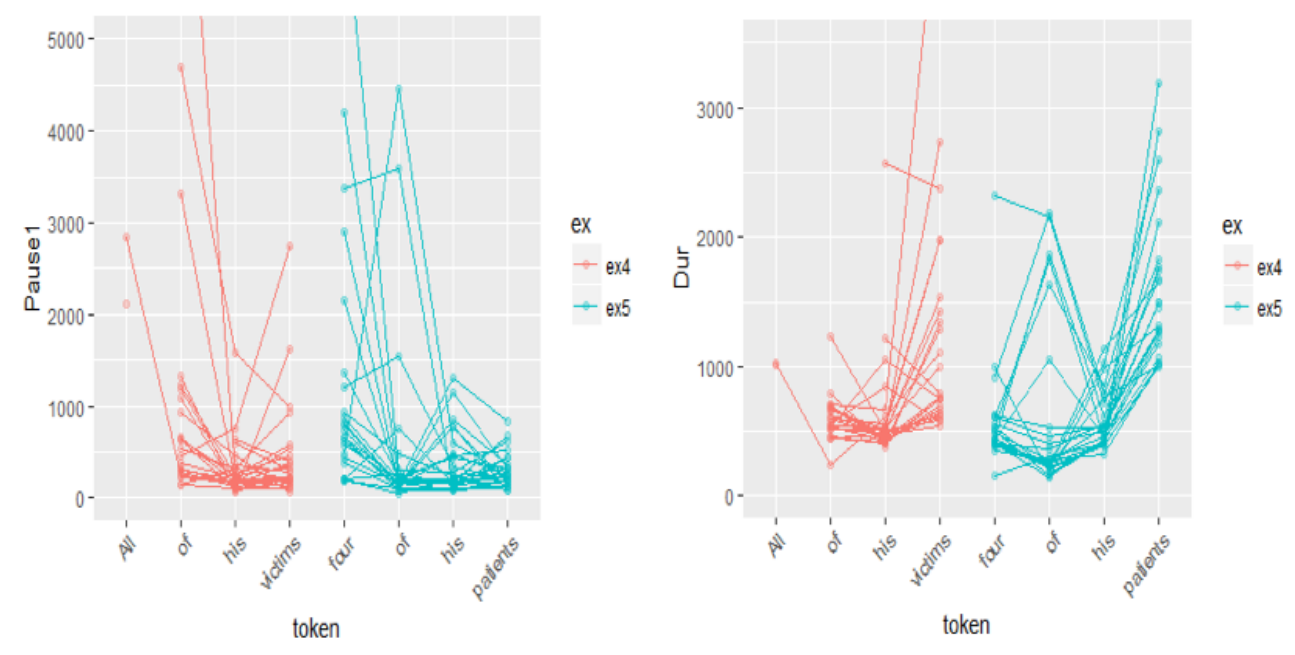

FIGURE 1: Pause1 per token and parti- FIGURE 2: Dur per token and participant. cipant.

the variables Duration, Pause, TrtS and TrtT. For Dur and Pause, and the patterns found are uniform. For Pause, the time decreases towards the end of the phrase, for Dur it increases towards the end of the phrase, and the increase is stronger for (5) than for (4).

A t-test on the data after log-transformation yielded a p-value of 0.269 for Dur and 0.324 for Pause, thus $p>0.05$ for both, i.e. the results are not statistically significant.

The patterns for reading times are shown in figures 3 and 4.

The reading times of the source yield two different patterns, an increasing trend from the beginning to the end of the phrase in (4), and a more U-shaped pattern in (5); the range of values seem roughly comparable in the two examples. The readings of the target look more different: although both patterns for TrtT look uniform throughout the phrase, with a slight increase towards the end, there is a lot of variation, especially in (5). The values for TrtT seem somewhat higher for (5) than for (4).

Comparing the boxplots for TrtS for the two phrases in figure 5 , the median value for (5) is found to be clearly higher than for (4).

The variation in (4) noted above is reflected in the inter-quartile range of (4) stretching far beyond the boundaries of the IQR of (5) on both sides.

Since the data is right-skewed, a log-transformed t-test was performed; yielding a p-value of 0.123 , hence the data provides no evidence to reject the null hypothesis that the mean of normalized TrtS is the same for (4) and (5).

The boxplots for TrtT in figure 6 show that the medians of mean normalized 


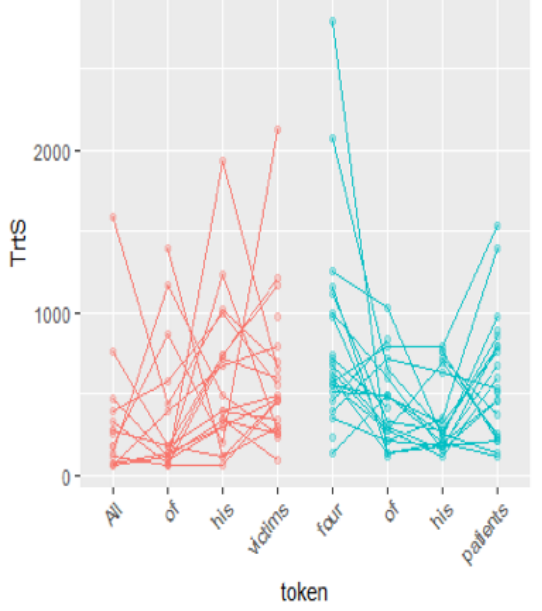

FIGURE 3: TrtS per token and participant.

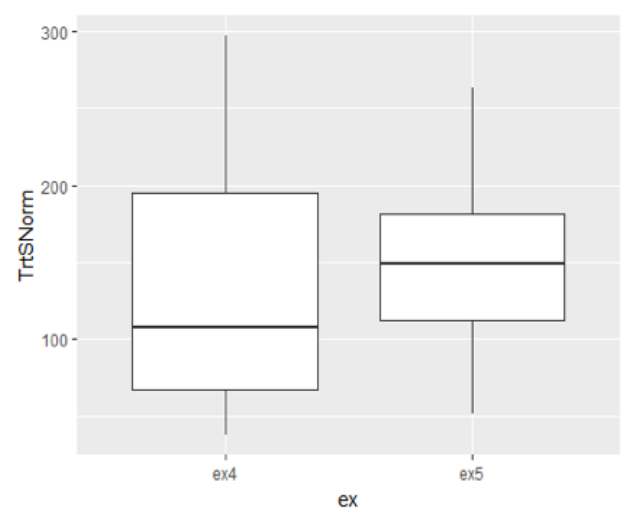

FIGURE 5: Normalized mean TrtS: (4) vs. FIGURE 6: Normalized mean TrtT: (4) vs. (5).

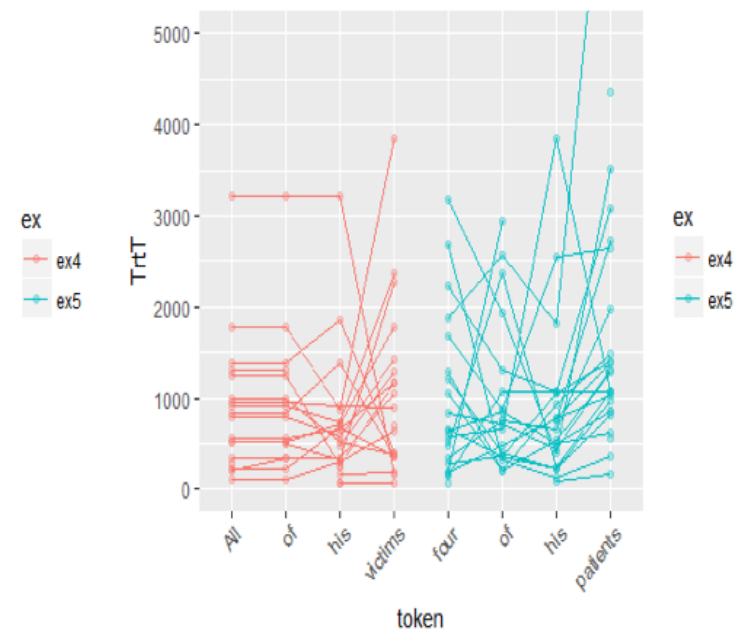

FIGURE 4: TrtT per token and participant.

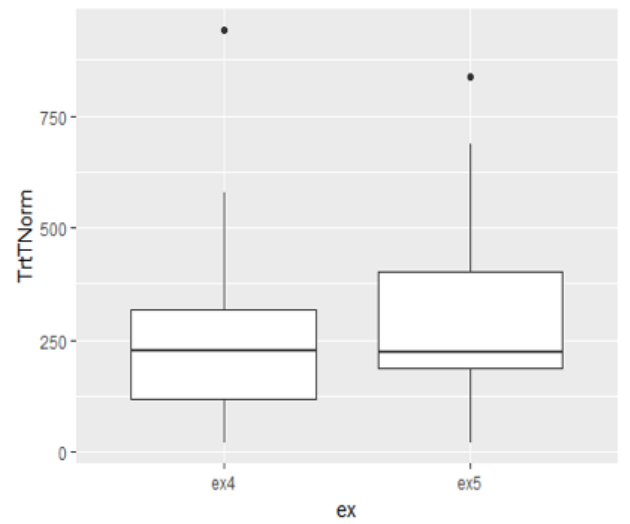

(5). 
TrtT are very similar for both examples. A t-test yielded a p-value of 0.504; hence the difference is not significant.

\section{[5.2] The Norwegian study: Absolute and statistical values}

Example 6: 'before returning to his car'

To start, absolute frequencies on choice of possessive for the individual examples are presented. For ease of reading, the example is repeated here:

(6) Exiting the vehicle, the driver reportedly kicked the prostrate animal before returning to his car, an onlooker claimed. (NO, sentence 3 ).

Table 6 shows the results on final choice of possessives in the Norwegian target.

\begin{tabular}{lrr}
\hline & Professionals & Students \\
\hline No possessive & 10 & 8 \\
Possessive (reflexive) & 2 & 5 \\
Possessive non-reflexive & 0 & 0 \\
\hline
\end{tabular}

TABLE 6: Results on translation of the possessive in (6).

There was hardly any hesitation in terms of edits among the participants. Only one (professional) edited his/her first choice with a reflexive possessive, deleted it, and then re-wrote it, changing from pre- to post-position. ${ }^{12}$ Нyротнеsis 3A and нуротнеsіs Зв are largely confirmed: Professionals and students alike tend to drop the possessive. Although different in the two groups, with a higher score for professionals, there is only a weak trend in the direction of the hypothesis.

Example 7: 'in his favorite parking spot outside his home...'

Table 7 shows the product results for (7), repeated below:

(7) The unnamed driver had found the dog sleeping in his favorite parking spot outside his home in Chongqing. (NO, sentence $\overline{2}$ )

The table demonstrates quite a variety of solutions, which confirms the first part of HYPOTHESIS 4B. On the one hand, there is a distinction between syntactic structures in the targets, some of which affect choice of possessive. On the other hand, whether the target choice retains the same structure as the source or not, there is considerable difference overall between the students and the professional translators. Most notable is the repetition of a possessive in the two noun phrases in target choices that have the same non-finite syntactic form as the source. This

[12] The pre- and post-positions of the reflexive in Norwegian were mentioned in section [2] as an option. This option has not been included in the present study. 


\begin{tabular}{llrr}
\hline Norwegian target & & Professionals & Students \\
\hline One possessive (same & SIN (refl.) & 4 & 0 \\
structure as in English) & HANS (non-refl.) & 0 & 1 \\
Two possessives (same & SIN-SIN & 0 & 3 \\
structure as in English) & HANS-HANS & 0 & 5 \\
& SIN-HANS & 0 & 1 \\
& HANS-SIN & 1 & 2 \\
No possessive (same struc- & & 1 & 0 \\
ture as in English) & & 6 & 1 \\
Restructuring into different & & & \\
finite forms & & 12 & 13 \\
Total & & \multicolumn{2}{c}{} \\
\hline
\end{tabular}

TABLE 7: Final solutions by professionals and students for (7).

occurs in 11/13 student translations, and only once among the professional translators. НурОтнЕSIS 4D - i.e. double possessives are expected to occur more often in the non-professionals' target text - was tested for significance using two $95 \%$ bootstrap intervals:

(i) Professionals: 95\% bootstrap confidence interval for percentage of 'double possessive' $=(0 ; 25)$

(ii) Students: $95 \%$ bootstrap confidence interval for percentage of 'double possessive' $=(58.3 ; 100)$

As the intervals do not overlap, the data provides convincing evidence that for the translation of this example, it is not mere chance that students use double possessive solutions more frequently than professionals. Based on these confidence intervals, the difference is at least a factor of 2.3.

The second part of HYPOTHESIS $4 \mathrm{~B}$ states that there will be more edits, reflecting more uncertainty, in the processing of the target in this example as compared to edits for (6) above. While only one edit was found for (6), table 8 shows that seven participants (three professionals and four students) edited their choice of possessives.

The variety in choice as well as the hesitations demonstrated by the edits for this example invited an analysis of the temporal measures for this example against measures of the same variables for (6), considering measures for the latter to form a reasonable base line. The comparative measures are intended to indicate to what extent the varieties in the counts in table 7 and 8 are reflected in our temporal 


\begin{tabular}{llrr}
\hline Solutions in target & Norwegian & No revision of POSS & Revision POSS \\
\hline ONE POSS & Professionals & 4 & 1 \\
& Students & 1 & 0 \\
TWO POSS & Professionals & 0 & 1 \\
& Students & 7 & 4 \\
NO POSS & Professionals & 0 & 1 \\
REFORMULATION & Professionals & 5 & 0 \\
& Students & 1 & 0 \\
Total & & 18 & 7 \\
\hline
\end{tabular}

TABLE 8: Edits by professionals and students for (7).

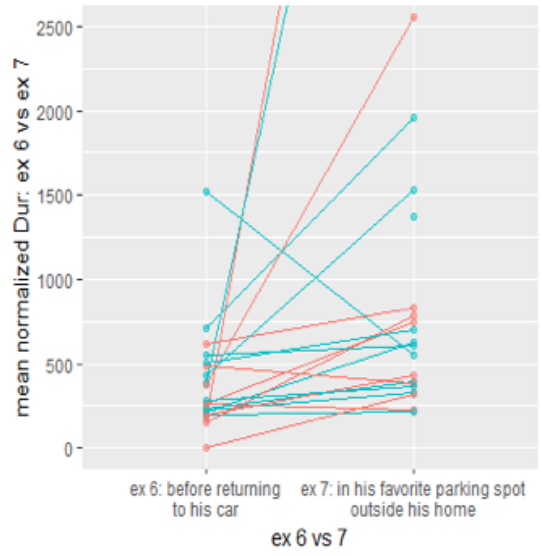

FIGURE 7: Normalized mean Dur of possessive phrase.

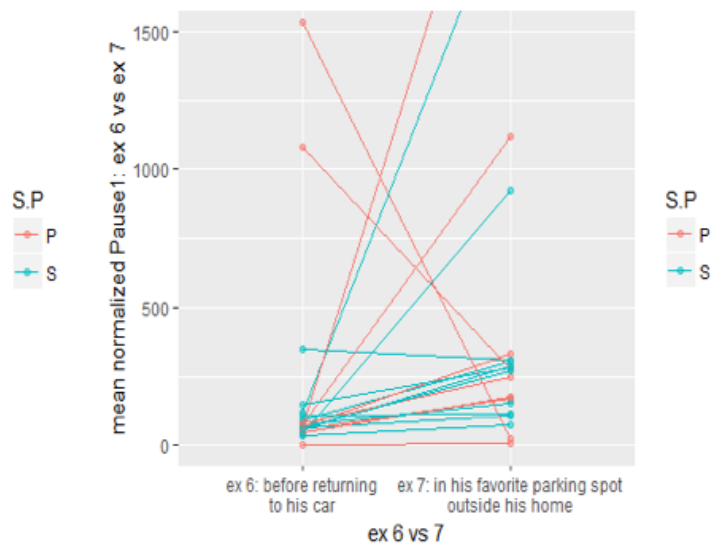

FIGURE 8: Normalized mean Pause1 of possessive phrase.

measures of translation effort. A one-sided paired t-test was made on the following specified hypotheses:

Null hypothesis For each of the variables Dur, Pause, TrtS, TrT, RPDur, and for each of the groups $\mathrm{S}$ (tudents) and $\mathrm{P}$ (rofessionals), the mean of the normalized measure taken over the phrase is the same for (7) and (6).

Alternative hypothesis The mean of the normalized temporal measure taken over the phrase is greater for (7) than for (6).

The normalized mean production duration and of the possessive phrase translation and the pause duration are plotted in figures 7 and 8.

The general trend is for both measures to be higher for (7) than for (6). The box plots below show that the median of the mean of the difference between (6) 


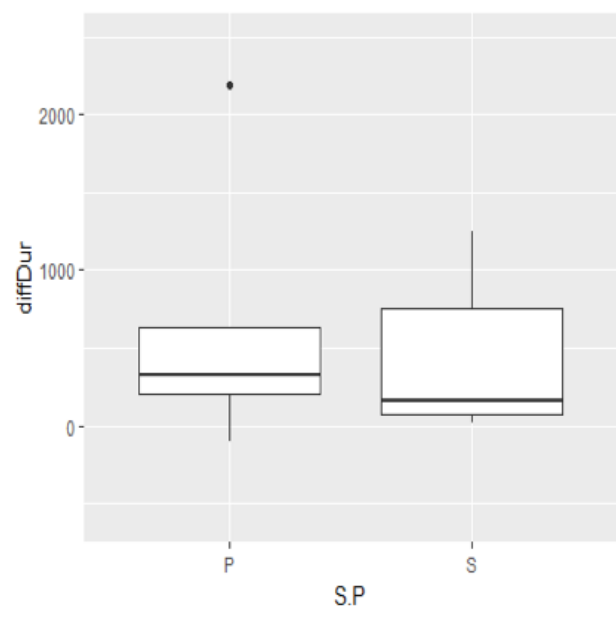

FIGURE 9: Difference in mean normalized Dur between (6) and (7).

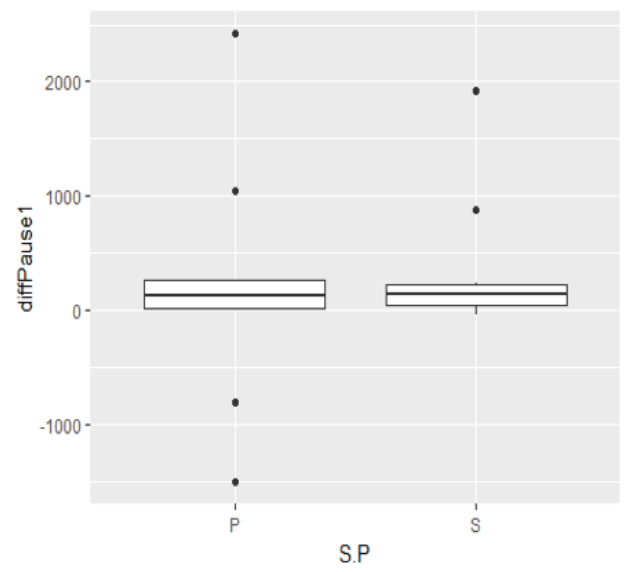

FIGURE 10: Difference in mean normalized Pause 1 between (6) and (7).

and (7) are greater than zero. It is higher for (7), as predicted by the hypothesis. Note that the difference is more marked in the group of professionals than in the student group. Box plots are provided in figures 9 and 10 .

T-tests on differences between (6) and (7) in the group of professionals yield: 0.073 for Dur and 0.296 for Pause. For the student group, $p$-value for $t$-tests on differences between (6) and (7) yield 0.097 for Dur and 0.042 for Pause. In sum, then, the Dur measures are not significant for either group, while the Pause measures are significant at $\mathrm{p}<0.05$ for the student group, but not for the professionals.

Plots for the variables reading time of the source and the target are shown in figures 11 and 12 .

Again, the general trend is for both measures to be higher for (7) than for (6), although there are some countrexamples. The most extreme is one professional in the TrtS, but there are also (slightly) negative values among students as well as professionals in TrtT. For TrtT there seem to be three types of differences, which also seem about equally likely in the two groups:

(i) TrtT is much larger for (7) than for (6), supporting the hypothesis

(ii) TrtT is slightly larger for (7) than for (6), also supporting the hypothesis

(iii) TrtT is slightly smaller for (7) than for (6), contradicting the hypothesis

The box plots for the participant results in figures 13 and 14 show that the median of the mean of the difference between (6) and (7) are greater than zero for both variables. 


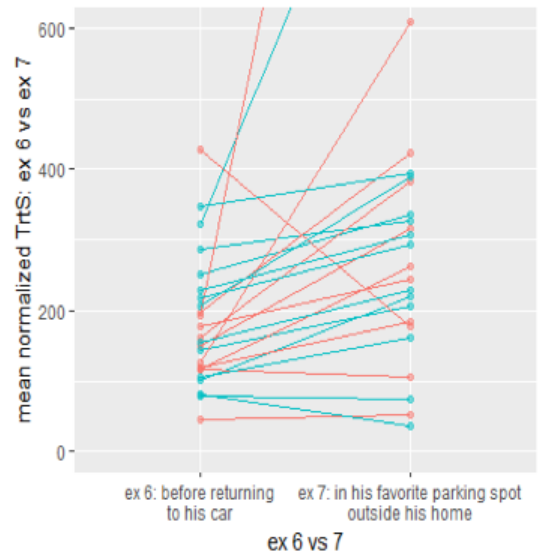

FIGURE 11: Normalized mean TrtS of possessive phrase.

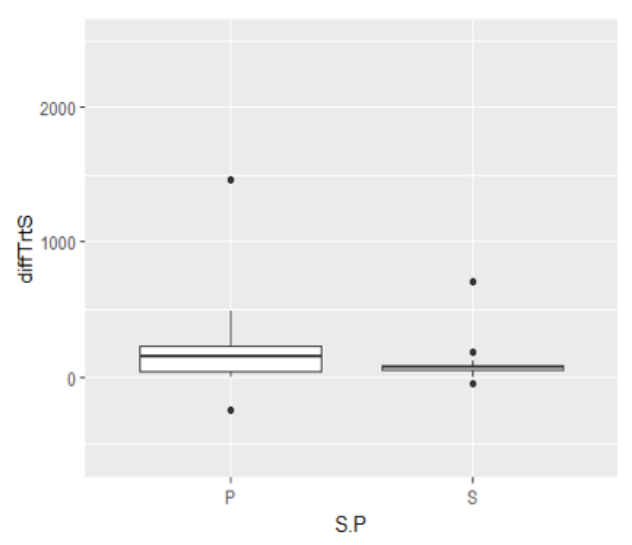

FIGURE 13: Difference in mean normalized TrtS between (6) and (7).

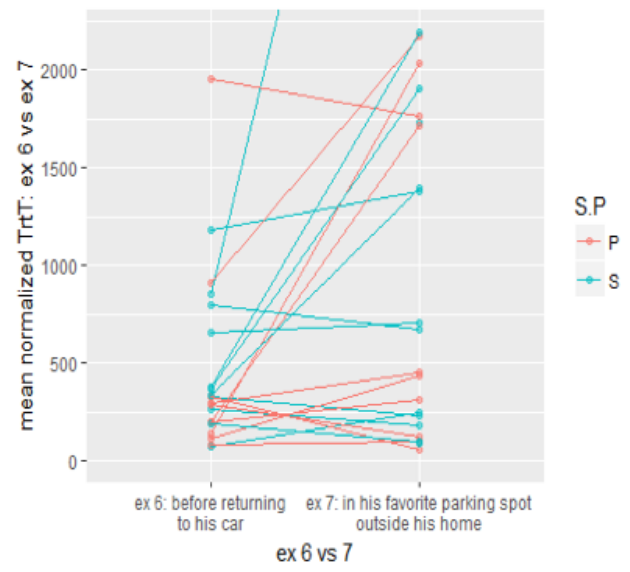

FIGURE 12: Normalized mean TrtT of possessive phrase.

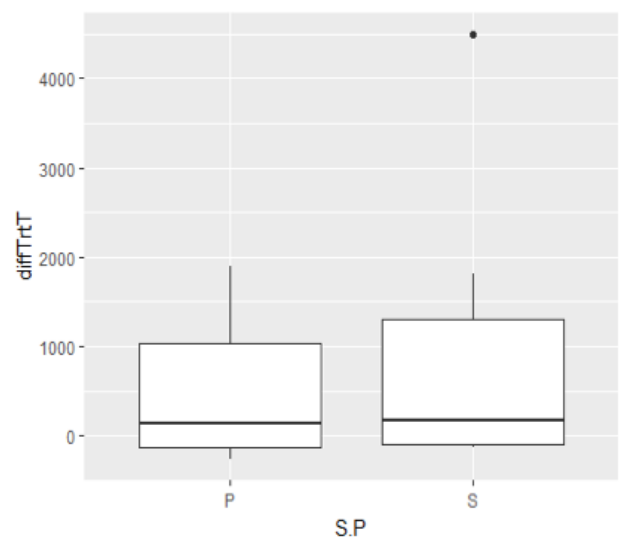

FIGURE 14: Difference in mean normalized TrtT between (6) and (7). 
It should be noted that there is very little variance in the student group for the reading of the source (TrtS), which differs from that of the professionals. For the reading of the target ( $\mathrm{TrtT}$, figure 14), the boxplot summaries look similar for $\mathrm{P}$ and $\mathrm{S}$ as the median difference is greater than zero, although only slightly and with the inter-quartile range ranging into negative values in both groups.

A t-test on TrtS for differences between (6) and (7) yields a p-value in the professional group at 0.056 ; hence $p>0.05$ and the difference is not significant. For the student group the t-test for the same difference yields $p=0.024$, hence the difference is highly significant in the direction of the hypothesis that the translation of (7) is more difficult than the translation of (6). For reading of the target (TrtT) the t-test gave a p-value of 0.047 for the professional group and 0.042 for the student group. Both $\mathrm{p}$-values are $<0.05$ in favor of the hypothesis that that translation of (7) takes longer than the translation of (6).

It should be noted that many of the $p$-values are relatively close to the significance level of $0.05(>0.04)$, but still significant. We are also cautious about the fact that all of the distributions in question are strongly right-skewed, which makes the t-test on small samples somewhat less reliable. Finally, outliers both in the positive and the negative direction are frequent; in view of the small sample of data, they can have a decisive influence.

\section{[5.3] Summing up the results}

For the Danish study, a subject phrase referring back to an antecedent in the previous sentence in (4) was solved in the same way by the two groups. Their choice is in accordance with the general rules stated in section [2] above. For (5), where the possessive occurred in a nominalization, there was considerable variation in the solutions, although the phrase as a whole distinguished two target structures: (i) a nominal structure equal to the source and (ii) a verbal, infinitive structure. The reflexive as well as the non-reflexive possessive was found in both structures. For the verbal alternative, there was a clear preference for the reflexive form, (SIN), (13/16 across participants). The non-reflexive (HANS) in this structure was found only in the student group. However, revision from a non-reflexive first choice to the reflexive was found in three participants overall. In the nominal version, choice between the reflexive and the non-reflexive was equally distributed between the two groups, and no edits were performed in the process. Any expected difference in the temporal measures between the two groups was disconfirmed by statistics. Also, no significant difference was found in the temporal measures between the processing of the apparently 'simpler' (4) and the more complex (5) for any of the groups.

The Norwegian examples were also compared on the assumption that there would be no hesitation on choice of possessive in the only, finite target solution to (6), but a variety of solutions and an expected uncertainty related to the formally 
(but not pragmatically) ambiguous (7). The simpler phrase in 6 was found to yield a difference between an expressed reflexive and no possessive, with a somewhat higher result on expressed reflexive in the student group. There was no choice of a non-reflexive form. On the other hand, a variety of solutions was found for the more complex structure in (7). Notably, $50 \%$ of the professional translators opted for a partial or total reformulation to ensure a syntactically unambiguous reading. Moreover, the choice of a double possessive in the structure was chosen only by one of the professional translators. The students opted for double possessives in $11 / 13$ cases. There was also a considerable amount of edits for (7), rather equally distributed between the two groups. It should be noted that many of the significant $p$-values are relatively close to the significance level of $0.05(>0.04)$. The fact that all of the distributions in question are strongly right-skewed admittedly makes the t-test on small samples somewhat less reliable. Finally, outliers - in the positive as well as the negative direction - are frequent; in view of the small sample of data, they can have a decisive influence. Their status is unclear: they may be the result of chance, or a sign of high inherent variability in all these measures.

Temporal measures were analyzed for questions of significant differences among the students and the professional translators for (7). All t-tests for differences in temporal measures yield p-values $>0.05$, thus there is no indication that the students struggled more than the professional translators. However, considering a comparison of the temporal measures for the two examples, the tests of Pause and total reading time of the source (TrtS) were significantly higher for the student group, and reading time of the target of (7) as compared with (6) (normalized for length) yielded a p-value $<0.05$ across participants, thus providing convincing evidence in favor of the hypothesis that (7) would take longer to process than (6) for both groups.

\section{[6] DISCUSSION AND RECOMMENDATIONS FOR FOLLOW-UP STUDIES}

\section{[6.1] Interpretation of the results}

The findings of the two studies are quite interesting in view of the general claim about the use of reflexive and non-reflexive possessives in Danish and Norwegian as well as in view of translation. The study indicates that there is a clear preference for the non-reflexive possessive in a structure where the possessive finds its antecedent in the previous sentence, such as in the Danish (4). The choice is uniform across participants, and follows the system as described in section [2]. Uniformity was also found for the finite structure in the Norwegian target of (6), as no participant chose the non-reflexive form in this example of a finite form with a local binder in the subject. However, there is variety in the choice of a reflexive or no mention of possession. The choice of dropping the reflexive possessive altogether was found to be the preferred one here. This is taken to mean that when possession is highly accessible in the immediate context, it is better left to 
inference than made explicit. This is also the case for (7), where a single possessive is adequate, as shown by the preference for one possessive among the professional translators. Double possessives were hypothesized to appear among the student solutions due to a lack of access to the pragmatic rules of Norwegian during the translation process. This hypothesis was confirmed.

However, the idea that students have been primed by the source is less clear. The choice of a non-reflexive possessive in the Danish verbal form in (5) may be an indication of priming among the students. No professional translators made this choice, there was no hesitation among these three students in terms of edits, and no significant difference in the temporal measures was found to suggest a translation problem with this choice. On the other hand, the judgement on errors is uncertain. Three other participants had the non-reflexive form as their first choice. This may mean that there is some uncertainty in the population with respect to binding conditions in non-finite structures. We will have to leave it open to further research to test choice of possessive in infinitive clauses in a systematic monolingual experiment to come closer to the question of priming in a translational setting.

The Norwegian translations of (7), apart from the reformulations already mentioned, are also cases of possessives in a non-finite structure. Here this study shows a variety of solutions among the students. The double possessive is particularly interesting: There does not seem to be a regular pattern of choice between the reflexive and the non-reflexive form. Also the temporal measures on reading the source, pausing and reading the target are strong indications that the students have reflected on the choice rather than just choosing the form most similar to the English one from a phonological perspective. It seems reasonable to interpret the results here as reflecting an uncertainty with respect to binding conditions when the possessive occurs in a non-finite clause structure. One particularly interesting example is (9) below. The student translator has the same syntactic form as the source in his/her translation, and ends up with a non-reflexive possessive in the first case and a reflexive in the second:

(9) P23 (stud): Den ikke navngitte sjåføren hadde funnet hunden sovende i favoritt-parkeringsplassen hans utenfor hjemmet sitt i Choongqin.

Lit.: 'The not named driver had found the dog sleeping in the favorite parking spot HANS outside the home SIN in Chongqing.'

The student's uncertainty is very clear. After spelling out the first translation with the non-reflexive in both phrases, s/he re-reads the target phrase, looks back to the source phrase four times without changing the target before $s /$ he goes on to the next phrase unit. This process takes 28.5 seconds. In the revision phase after the first draft of the whole translation, s/he stops again at the relevant phrases, reads and re-reads the target several times, revises the first possessive 
twice and the second once. The process takes 58.8 seconds, almost one minute. Before stopping at the end of the revision of the whole translation, the participant takes a final brief look at this particular phrase, with no change, viz. (10):

$$
\begin{aligned}
& \text { i hans [snah] } \sin [\text { nis]hans[snah] favorittparkeringplass oute } \\
& \text { [etuo]en hans[snah] } \sin ^{13}
\end{aligned}
$$

It is interesting to see that this informant has a clearly wrong choice of preposition in the first phrase: the preposition chosen is the one phonologically most similar to the English source ( $i$ for in), and not the correct $p a$. This may be indicative of hard concentration around the possessive.

The comparison of the student group and the group of professionals is interesting in view of the double possessive choice among the students. The fact that duration as well as pause measures for the phrase were significantly higher for the student group as compared with the same measure for (6) is no evidence that the processing of the phrase is an effect of priming. On the contrary, hesitation as measured through pauses and edits may well be interpreted as a general learner effect, as discussed in section [2].

Temporal measures in TrtT among the professionals were also found to be significantly higher for (7) than for (6). The fact that temporal measures indicate no processing difficulties in the reading of the source (relative to (6)) suggests a formulation problem rather than a comprehension problem. The high number of restructured solutions supports this view. Examples of restructured targets are partial or total changes of the syntax, typically choices with finite structures (i.e. with subjects) which make only one reading available (cf. (11) and (12), or the non-mention of possession, leaving the interpretation of ownership to pragmatic inference (cf. (13):

P07, PROFESSIONAL

Den ikke navngitte sjåføren hadde kommet over hunden, der den lå og sov på parkeringsplassen han brukte foran sin hjem i Chongqing.

Lit.: 'The unnamed driver had come across the dog, where it lay and slept in the parking spot $h e^{14}$ used in front of SIN home in Chongqing.'

(12) P13, PROFESSIONAL

Den ukjente bilisten hadde oppdaget hunden, som lå og sov på bilens vante parkeringsplass, utenfor huset hans i Chongqing.

Lit.: 'The unknown driver had discovered the dog, who lay and slept on the car's usual parking spot outside the house HANS in Chongqing.'

[13] The reverse form of the possessives in the square brackets is a representation of the deletions (from end to beginning).

[14] Italics have been used to show the subject within the finite clause. I note that the choice of reflexive appears with the incorrect gender relative to its possessum, but this is irrelevant for the point made here. 

P04, PROFESSIONAL
Sjåføren, som kan forbli navnløs, hadde funnet hunden sovende på park- eringsplassen utenfor hjemmet i Chongquing.
Lit.: 'The driver, who will remain nameless, had found the dog sleeping in the parking spot outside the home in Chongqing.'

In conclusion, the present study gives strong support to the general rule that the reflexive possessive is the only correct choice when it is controlled by the (expressed) subject of its clause (cf. (6)). It also supports the general rule that the non-possessive is the only correct choice when it finds its antecedent across sentence boundaries ((4)), or it appears in a finite subordinate clause with its antecedent in the matrix (the translation solution in (11)). When it comes to nonfinite clauses such as the infinitive clause translations of (5), and the participial clause translations of (7), as well as the nominalization translations of (6), the rule is far from clear, according to the native target language translators. On this account, it would not be surprising that learners of Danish or Norwegian whose first language does not make the contrast between reflexive and non-reflexive possessives should find it hard to acquire the possessive system in these languages, as demonstrated in Hellan as well as Pitz et al. (2017). Follow-up studies may inform us on the preferences among native Norwegian speakers. Only then can we decide whether the indecisions and processing difficulties demonstrated in the present study are due to translation blocking access to the target system or to the target system itself.

\section{[6.2] Limitations of the study}

While the behavioral measures in terms of processing times have been very helpful in understanding some of the linguistic problems translators meet, the analyses admittedly have clear limitations. One problem, quite general in translation process research, is the small size of the population studied. When furthermore individual variation is considerable, as in the present study, it is hard to draw very definite conclusions. Edits, on the other hand, in comparison with the final products, are better indicators of the problem, although again, the small sample problem has not been solved.

The reader may have wondered why the present study has computed temporal measures based on whole phrases as a unit rather than on the possessive alone. A weakness of such an approach is that the lexical items in the various examples differ, and some of the measures may therefore be due to problems with lexical choice rather than problems with the choice of possessive. Admittedly, this is a problem. However, there are three arguments for choosing the phrase measure over the word measure. First, even though the background for starting eye tracking as a method of studying reading and translation is based on the long-held eye-mind 
hypothesis of Just \& Carpenter (1980) - that what you look at is what you think about, no eye tracking system to date is precise enough to avoid some skewing. The result is that some manual revision has to be made to the best of our understanding, in the hope that the measures come closer to what is actually being read when skewing is obvious. The second argument is that processing for interpretation often takes place after the word has been read: the reader needs a context to restrict the meaning or find the reference of a word. Finally, the fact that function words are often not fixated, but content words are, as well as the fact that the eye observes some letters to the left and to the right of what they focus on can only be interpreted to mean that the participant interprets and makes a translation hypothesis about the possessive to the left of the content word s/he looks at.

Finally, the study's analyses rely to some extent on descriptive statistics. While this makes good sense in many places, it makes generalizability somewhat problematic. A follow-up study might benefit from inferential statistical testing of the results (cf. Hvelplund (2016)).

\section{[6.3] Follow-up studies}

While the present study has made a thorough investigation into Scandinavian native speakers' translation of possessives from English, there is clearly a need to make a systematic study of native Scandinavian preferences of reflexive and nonreflexive possessives in non-finite and other clause structures in a monolingual setting. One such work is on its way (Behrens \& Dirdal To appear), in which sentences with the same lexical units are varied for non-finite, nominalized and finite structures and tested for interpretation and acceptability in a Norwegianonly experiment. A parallel translation test has been worked out. A comparison of the two can give more precise results on preferences in a monolingual setting and give us more precise information on a possible distinction between native speaker judgments in monolingual setting and in translation.

APPENDIX: THE SOURCE TEXTS USED IN THE TWO TRANSLATION EXPERIMEN TS

$D A$

Killer nurse receives four life sentences.

Hospital nurse Colin Norris was imprisoned for life today for the killing of four of his patients. 32 year old Norris from Glasgow killed the four women in 2002 by giving them large amounts of sleeping medicine. Yesterday, he was found guilty of four counts of murder following a long trial. He was given four life sentences, one for each of the killings. He will have to serve at least 30 years.

Police officer Chris Gregg said that Norris had been acting strangely around the hospital. Only the awareness of other hospital staff put a stop to him and to the 
killings. The police have learned that the motive for the killings was that Norris disliked working with old people. All of his victims were old, weak women with heart problems. All of them could be considered a burden to hospital staff.

NO

A stray dog in China proved that revenge is a dish best served cold after damaging the car of the driver who kicked it. The unnamed driver had found the dog sleeping in his favorite parking spot outside his home in Chongqing. Exiting the vehicle, the driver reportedly kicked the prostrate animal before returning to his car, an onlooker claimed. But that was not the end. The animal later returned - with reinforcements - and proceeded to attempt to rip apart the car's bodywork, tearing off the wind-screen wipers, and scratching the paint. The attack of the hounds was captured on camera by an astonished neighbor.

China is home to about 130 million dogs, many of them pampered pets. As the middle class expands, rising numbers of pet owners have resulted in increased opposition to animal cruelty. Unfortunately, there is still scant legislation protecting animals' rights.

\section{REFERENCES}

Bangalore, Srinivas, Bergljot Behrens, Michael Carl, Maheshwar Ghankot, Arndt Heilmann, Jean Nitzke, Moritz Schaeffer \& Annegret Sturm. 2015. Syntactic variance and priming effects in translation. In Moritz Schaeffer \& Michael Carl (eds.), New directions in empirical translation process research, 211-238. Cham: Springer.

Behrens, Bergljot. 2006. Language-based processing in advanced L2 and translation into L1. In Heidi Byrnes, Heather Weger-Guntharp \& Katherine A. Sprang (eds.), Educating for advanced foreign language capacities: Constructs, curriculum, instruction, assessment, 74-86. Washington: Georgetown University Press.

Behrens, Bergljot \& Hildegunn Dirdal. To appear. Preferences in choice of Norwegian possessives. Oslo Studies in Language.

Carl, Michael, Moritz Schaeffer \& Srinivas Bangalore. 2015. The CRITT translation process research database. In Moritz Schaeffer \& Michael Carl (eds.), New directions in empirical translation process research, 13-54. Cham: Springer.

Carroll, Mary \& Christiane von Stutterheim. 1993. The representation of spatial configurations in English and German, and the grammatical structure of locative and anaphoric expressions. Linguistics 31. 1011-1041.

Faarlund, Jan Terje, Svein Lie \& Kjell Ivar Vannebo. 1997. Norsk referansegrammatikk. Oslo: Universitetsforlaget. 
Fabricius-Hansen, Cathrine, Hans Petter Helland \& Anneliese Pitz. 2017. An L2 perspective on possessives: Contrasts and their possible consequences. Oslo Studies in Language 9(2). 3-39.

Glaser, Robert \& Michelene T. H. Chi. 1988. Overview. In Michelene T. H. Chi, Robert Glaser \& Marshall J. Farr (eds.), The nature of expertise, xv-xxviii. Mahwah, New Jersey: Lawrence Erlbaum.

de Groot, Annette M. B. 1992. Bilingual lexical representation: A closer look at conceptual representations. In R. Frost \& L. Katz (eds.), Orthography, phonology, morphology, and meaning, 389-412. Amsterdam: Elsevier.

Grosjean, Francois. 1997. The bilingual individual. Interpreting - International Journal of Research and Practice in Interpreting 2. 163-187.

Günthner, Susanne. 2011. Between emergence and sedimentation: Projecting constructions in German interactions. In Peter Auer \& Stefan Pfänder (eds.), Constructions: Emerging and emergent, 156-185. Berlin: De Gruyter.

Helland, Hans Petter. 2017. An empirical L2 perspective on possessives: French/Norwegian. Oslo Studies in Language 9(2). 75-104.

Huddleston, Rodney \& Geoffrey K. Pullum. 2002. The Cambridge grammar of the English language. Cambridge: Cambridge University Press.

Hvelplund, Kristian Tangsgaard. 2011. Allocation of cognitive resources in translation: An eye-tracking and key-logging study.

Hvelplund, Kristian Tangsgaard. 2016. Cognitive efficiency in translation. In Ricardo M. Martín (ed.), Reembedding translation process research, 149-170. Amsterdam: Benjamins.

Jakobsen, Arnt Lykke \& Kristian Tangsgaard Hvelplund Jensen. 2008. Eye movement behaviour across four different types of reading task. Copenhagen Studies in Language 36. 103-124.

Just, Marcel Adam \& Patricia A. Carpenter. 1980. A theory of reading: From eye fixations to comprehension. Psychological Review 87(4). 329-354.

Jääskeläinen, Riitta. 2010. Are all professionals experts? definitions of expertise and reinterpretation of research evidence in process studies. In Gregory M. Shreve \& Erik Angelone (eds.), Translation and cognition, 213-227. Amsterdam: Benjamins.

Kinn, Torodd. 2014. Verbalt presens partisipp. Norsk Lingvistisk Tidsskrift 32(1). 62-99. 
Koessler, Maxime \& Jules Derocquigny. 1928. Les faux amis; ou, les trahisons du vocabulaire anglais. Paris: Vuibert.

Kroll, Judith F. \& Annette M. B. de Groot. 1997. Lexical and conceptual memory in the bilingual: Mapping form to meaning in two languages. In Annette M. B. de Groot \& Judith F. Kroll (eds.), Tutorials in bilingualism: Psycholinguistic perspectives, 169-199. Mahwah, New Jersey: Lawrence Erlbaum.

Lundquist, Björn. 2014. Mid-distance binding: Binding into infinitival clauses. Nordic Atlas of Language Structure 1.

Pitz, Anneliese, Oliver Bott, Torgrim Solstad, Robin Hörnig, Bergljot Behrens \& Cathrine Fabricius-Hansen. 2017. An empirical L2 perspective on possessives: German/Norwegian. Oslo Studies in Language 9(2). 41-74.

Ydstie, Jo Terje. 1998. Oversatt norsk - unaturlig norsk? Working Papers in Applied Linguistics 4(98). 170-198. 